\title{
Eröffnung der Publikumsausstellung im Röntgen-Geburtshaus
}

Am 27. März 2019 ist es soweit: Die Publikumsausstellung im Geburtshaus von Wilhelm Conrad Röntgen wird eröffnet. Dank der großzügigen Unterstützung von Mitgliedern, Partnern, Sponsoren, der NRW-Stiftung sowie dem Landschaftsverband Rheinland konnte dieser erste Teilabschnitt der Neugestaltung realisiert werden. Die Ausstellung im Erdgeschoss des historischen Gebäudes in Remscheid-Lennep widmet sich dem Leben und Wirken des berühmten Forschers. In einer Schatzkammer erwarten die Besucherinnen und Besucher ausgewählte Originale, wie etwa die Briefe berühmter Persönlichkeiten, die an Röntgen schrieben. Die Ausstellung wird öffentlich und kostenfrei zugänglich sein und soll dazu beitragen, das Haus in ein lebendiges Denkmal für Interessierte aus Nordrhein-Westfalen, Deutschland und der ganzen Welt zu verwandeln.

Das gesamte Haus mit Tagungs- und Konferenzmöglichkeiten sowie einem Apparte-

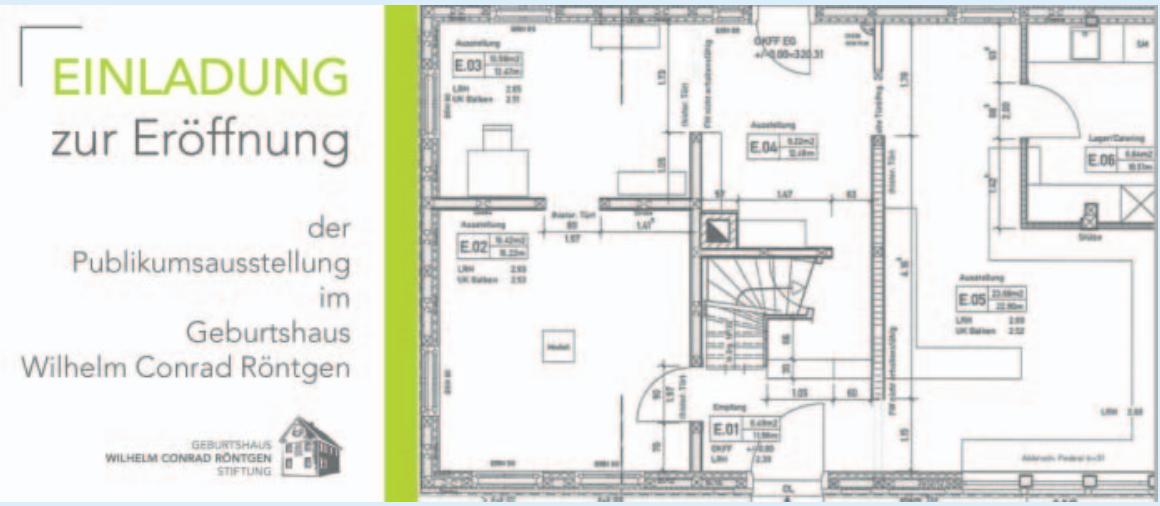

ment für Wissenschaftler und Gäste soll schulen, Städte, Gesellschaften, Verbände zum Röntgen-jubiläumsjahr 2020 eröffnet werden. Denn Wilhelm Conrad Röntgen würde im kommenden Jahr seinen $175 \mathrm{Ge}$ burtstag begehen, und seine Entdeckung der „X-Strahlen“ jährt sich zum 125. Mal. Um dieses bedeutsame Kapitel deutscher Wissenschaftsgeschichte einem Fachpublikum und der breiten Öffentlichkeit nahe zu bringen, haben sich Universitäten, Hoch- und Institutionen zusammengeschlossen.

Mehr Informationen zum RöntgenGeburtshaus und Unterstützungsmöglichkeiten finden Sie online unter www. roentgen-geburtshaus.de. 